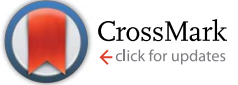

Cite this: Chem. Sci., 2017, 8, 1075

Received 11th July 2016

Accepted 8th September 2016

DOI: $10.1039 / c 6 s c 03039 d$

www.rsc.org/chemicalscience

\section{Reactivity of the copper(III)-hydroxide unit with phenols $\uparrow$}

\author{
Debanjan Dhar, $\neq^{\mathrm{a}}$ Gereon M. Yee,,$^{\mathrm{a}}$ Todd F. Markle, ${ }^{\mathrm{b}}$ James M. Mayer ${ }^{\star b}$ \\ and William B. Tolman*a
}

Kinetic studies of the reactions of two previously characterized copper(III)-hydroxide complexes ( $\mathrm{LCuOH}$ and ${ }^{\mathrm{NO}_{2}} \mathrm{LCUOH}$, where $\mathrm{L}=N, N^{\prime}$-bis(2,6-diisopropylphenyl)-2,6-pyridine-dicarboxamide and ${ }^{\mathrm{NO}_{2}} \mathrm{~L}=N, N^{\prime}$ bis(2,6-diisopropyl-4-nitrophenyl)pyridine-2,6-dicarboxamide) with a series of para substituted phenols ( ${ }^{\mathrm{ArOH}}$ where $\mathrm{X}=\mathrm{NMe}_{2}, \mathrm{OMe}, \mathrm{Me}, \mathrm{H}, \mathrm{Cl}, \mathrm{NO}_{2}$, or $\mathrm{CF}_{3}$ ) were performed using low temperature stoppedflow UV-vis spectroscopy. Second-order rate constants $(k)$ were determined from pseudo first-order and stoichiometric experiments, and follow the trends $\mathrm{CF}_{3}<\mathrm{NO}_{2}<\mathrm{Cl}<\mathrm{H}<\mathrm{Me}<\mathrm{OMe}<\mathrm{NMe}_{2}$ and $\mathrm{LCuOH}$ $<\mathrm{NO}_{2} \mathrm{LCuOH}$. The data support a concerted proton-electron transfer (CPET) mechanism for all but the most acidic phenols $\left(\mathrm{X}=\mathrm{NO}_{2}\right.$ and $\left.\mathrm{CF}_{3}\right)$, for which a more complicated mechanism is proposed. For the case of the reactions between ${ }^{\mathrm{NO}}{ }_{2} \mathrm{ArOH}$ and $\mathrm{LCUOH}$ in particular, competition between a CPET pathway and one involving initial proton transfer followed by electron transfer (PT/ET) is supported by multiwavelength global analysis of the kinetic data, formation of the phenoxide ${ }^{\mathrm{NO}_{2}} \mathrm{ArO}^{-}$as a reaction product, observation of an intermediate $\left[\mathrm{LCu}\left(\mathrm{OH}_{2}\right)\right]^{+}$species derived from proton transfer from ${ }^{\mathrm{NO}_{2}} \mathrm{ArOH}$ to $\mathrm{LCUOH}$, and thermodynamic arguments indicating that initial PT should be competitive with CPET.

\section{Introduction}

Detailed study of the structural and spectroscopic properties and reactivity of copper-oxygen complexes can provide important insights into the nature of putative intermediates in oxidation catalysis. ${ }^{1}$ We recently identified a new copper-oxygen motif comprising a $[\mathrm{CuOH}]^{2+}$ core, examples of which $(\mathbf{2 a - c})$ were prepared in solution via the one-electron oxidation of anionic copper(II)-hydroxide complexes 1a-c at low temperature (Scheme 1). ${ }^{\mathbf{1 f}, \mathbf{2}}$ Complexes $\mathbf{2 a}-\mathbf{c}$ were postulated on the basis of spectroscopy and theory to be best described as copper(III)hydroxide species, and may be viewed formally as protonated versions of the $[\mathrm{CuO}]^{+}$unit that has been characterized in the gas phase ${ }^{3}$ and by theory. ${ }^{\mathbf{4} \boldsymbol{3 b}, \mathbf{3 d} \boldsymbol{d}}$ Despite their weak oxidizing ability (2a: $E_{1 / 2}=-0.074 \mathrm{~V} v s$. $\mathrm{Fc}^{+} / \mathrm{Fc}$ in THF), the complexes react rapidly with $\mathrm{C}-\mathrm{H}$ bonds of added organic substrates; for example, dihydroanthracene (DHA) is converted cleanly to anthracene at high rates $\left(e . g\right.$. for $2 \mathrm{a}, k=1.1(1) \mathrm{M}^{-1} \mathrm{~s}^{-1}$ at $-80{ }^{\circ} \mathrm{C}$

${ }^{a}$ Department of Chemistry, Center for Metals in Biocatalysis, University of Minnesota, 207 Pleasant St. SE, Minneapolis, MN 55455, USA. E-mail: wtolman@umn.edu

${ }^{b}$ Department of Chemistry, Yale University, New Haven, Connecticut 06520-8107, USA. E-mail: james.mayer@yale.edu

$\dagger$ Electronic supplementary information (ESI) available: Includes experimental details, synthesis and preparation of $\left[\mathrm{Bu}_{4} \mathrm{~N}\right]\left[\mathrm{NO}^{2} \mathrm{ArO}\right]$ and $\left[\mathrm{Bu}_{4} \mathrm{~N}\right]\left[\mathrm{LCu}^{\mathrm{NO}_{2}} \mathrm{ArO}\right]$, kinetic plots, and spectroscopic data (PDF), as well as X-ray crystallographic data for $\left[\mathrm{Bu}_{4} \mathrm{~N}\right]\left[\mathrm{LCu}^{\mathrm{II}} \mathrm{OAr}^{\mathrm{NO}_{2}}\right]$ (CIF). CCDC 1491843. For ESI and crystallographic data in CIF or other electronic format see DOI: 10.1039/c6sc03039d

\$ These authors made equal contributions to this work. in $\left.\mathrm{CH}_{2} \mathrm{Cl}_{2}\right)$, ${ }^{2 c}$ with concomitant formation of the respective copper(II)-aqua complex (3a-c). The $\mathrm{O}-\mathrm{H}$ bond dissociation enthalpies (BDE) in 3a-c were experimentally determined to lie in the range $88-91 \mathrm{kcal} \mathrm{mol}^{-1},{ }^{2 b, c}$ high values that rationalize, at least in part, the fast rates of reactions of $\mathbf{2 a - c}$ with DHA and the observation that even stronger $\mathrm{C}-\mathrm{H}$ bonds may be attacked, including those of cyclohexane $\left(\mathrm{C}-\mathrm{H} \mathrm{BDE} \sim 99 \mathrm{kcal} \mathrm{mol}^{-1}\right)$. The

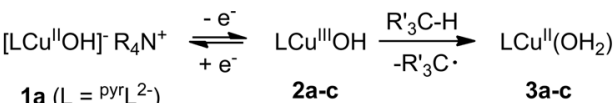

$$
\begin{aligned}
& 1 b\left(L=\mathrm{NO}^{2} L^{2-}\right) \\
& \text { 1c }\left(L={ }^{p i p} L^{2-}\right)
\end{aligned}
$$

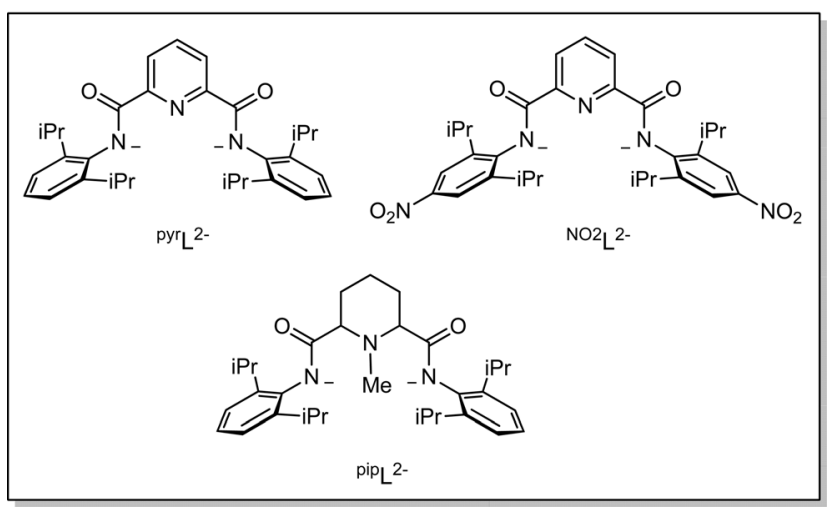

Scheme 1 Synthesis and reactivity of copper(III)-hydroxo complexes. 
high $\mathrm{O}-\mathrm{H}$ BDE values for $3 \mathbf{a}-\mathbf{c}$ arise from high basicity of the hydroxide $\left(\mathrm{p} K_{\mathrm{a}}(3 \mathrm{a})=18.8 \pm 1.8 \text { in } \mathrm{THF}\right)^{2 b}$ offsetting the poor oxidizing power of the complexes, properties which may be traced to the strongly electron donating bis(carboxamido) supporting ligands. Kinetics data and computations support the notion that the reactions of $\mathbf{2 a - c}$ with organic substrates involve hydrogen atom transfer (HAT) from organic substrates to the $[\mathrm{CuOH}]^{2+}$ unit with a significant tunneling contribution to the

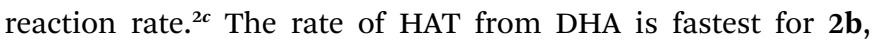
which has a slightly higher $\mathrm{O}-\mathrm{H}$ BDE in the corresponding reaction product $(\mathbf{3 b})$ as a result of a higher reduction potential that offsets its weaker basicity. ${ }^{2 c}$ Importantly, the observed high reactivity of the copper(III)-hydroxide core in $\mathbf{2 a - c}$ provides key precedence for its possible involvement as an intermediate in oxidation catalysis.

The extent of coupling of the proton and electron for a HAT reaction involved in attack at $\mathrm{X}-\mathrm{H}(\mathrm{X}=\mathrm{C}, \mathrm{N}, \mathrm{O})$ bonds by transition metal oxo/hydroxo species is a fundamentally important mechanistic issue, particularly in view of the significance of atom transfer reactions in biology and catalysis. ${ }^{5}$ Two extremes may be envisioned: concerted proton-electron transfer (CPET) or sequential proton and electron transfer (PT/ET or $\mathrm{ET} / \mathrm{PT}$ depending on which occurs first). For reactions with $\mathrm{C}-\mathrm{H}$ bonds of substrates that are relatively difficult to oxidize (remove electrons) or deprotonate, the sequential processes are disfavored and tightly coupled, or CPET paths are typical (although there are exceptions). ${ }^{6}$ A CPET mechanism is consistent with the available evidence for the reactions of the copper(III)-hydroxide complexes 2 a-c with $\mathrm{C}-\mathrm{H}$ bonds. ${ }^{2}$ We hypothesized, however, that the high basicity of the hydroxide ligands in these complexes might underlie some contributions from $\mathrm{PT} / \mathrm{ET}$ processes in reactions with more acidic $\mathrm{N}-\mathrm{H}$ or $\mathrm{O}-\mathrm{H}$ bonds. In order to test this notion, we chose to examine the reactivity of $\mathbf{2 a}$ and $\mathbf{b}$ with phenols, substrates that have garnered extensive attention because of their importance in biological proton, electron, and atom transfer processes. ${ }^{7}$ By varying the para substituents on the phenols, the reduction potentials and acidity of the phenols could be varied over a significant range (Scheme 2 and Table 1), enabling these effects on the reaction rates to be evaluated for the two

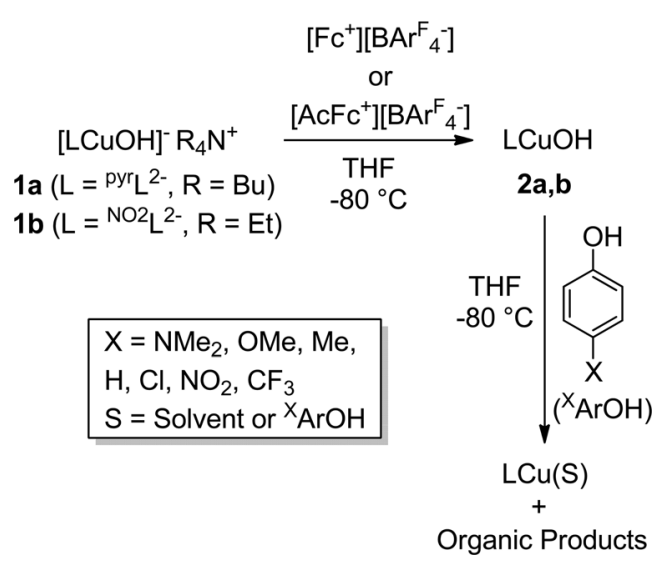

Scheme 2 Reactions studied in this work.
Table 1 Properties of phenols ${ }^{\mathrm{x}} \mathrm{ArOH}^{a}$

\begin{tabular}{llllll}
\hline $\mathrm{X}$ & $\begin{array}{l}\mathrm{BDFE} \\
\left(\mathrm{kcal} \mathrm{mol}^{-1}\right)\end{array}$ & $\begin{array}{l}\mathrm{p} K_{\mathrm{a}} \\
(\mathrm{ROH})\end{array}$ & $\begin{array}{l}E_{1 / 2} \\
\left(\mathrm{RO} / \mathrm{RO}^{-}\right)^{b}\end{array}$ & $\begin{array}{l}\mathrm{p} K_{\mathrm{a}} \\
\left(\mathrm{ROH}^{+}\right)\end{array}$ & $\begin{array}{l}E_{1 / 2} \\
\left(\mathrm{ROH}^{+} / \mathrm{ROH}\right)^{b}\end{array}$ \\
\hline $\mathrm{NMe}_{2}$ & 78.7 & 19.8 & -0.847 & 6.3 & -0.045 \\
$\mathrm{OMe}$ & 83.0 & 19.1 & -0.618 & -5.6 & 0.850 \\
$\mathrm{Me}$ & 87.1 & 18.9 & -0.428 & -4.0 & 1.10 \\
$\mathrm{H}$ & 88.3 & 18.0 & -0.325 & -7.7 & 1.20 \\
$\mathrm{Cl}$ & 88.7 & 16.75 & -0.232 & -11 & 1.40 \\
$\mathrm{NO}_{2}$ & 93.1 & 10.8 & 0.314 & -9.5 & 1.90 \\
$\mathrm{CF}_{3}$ & 93.7 & $15.2^{c}$ & $0.079^{c}$ & - & -
\end{tabular}

${ }^{a}$ Measured in DMSO, from ref. 8 unless otherwise stated. ${ }^{b} \mathrm{~V} v s . \mathrm{Fc}^{+} / \mathrm{Fc}$. ${ }^{c}$ From ref. 9.

complexes $2 \mathbf{a}$ and $\mathbf{b}$, that have different $\mathrm{O}-\mathrm{H}$ BDE's (in the corresponding copper(II)-aqua complexes $\mathbf{3 a}$ and $\mathbf{3 b}$ ) and DHA reaction rates. ${ }^{2 c}$ Herein we report the results of these reactivity studies, and in particular the findings from kinetics experiments that implicate CPET processes for all but the most acidic phenol substrates, for which evidence is provided that PT/ET is involved. The results expand upon previous work ${ }^{2}$ defining the kinetics and thermodynamics of reactions of the $[\mathrm{CuOH}]^{2+}$ unit that is important for understanding its potential involvement in oxidation catalysis.

\section{Results}

\section{Stopped-flow kinetics experiments}

The reactions of the copper(III)-hydroxide complexes $2 \mathbf{a}$ and b with phenols ${ }^{\mathrm{x}} \mathrm{ArOH}$ were monitored using double-mixing stopped-flow UV-vis spectroscopy at $-80^{\circ} \mathrm{C}$ in THF. In a typical experiment, in the first mixing event equimolar solutions of the copper(II)-hydroxide complex (1a or b) were combined in a $1: 1$ ratio with the appropriate oxidant in $\operatorname{THF}\left([\mathrm{Fc}]\left[\mathrm{BAr}_{4}{ }_{4}\right]\right.$ in the case of $\mathbf{1 a}$; $[\mathrm{AcFc}]\left[\mathrm{BAr}_{4}^{\mathrm{F}}\right.$ ] in the case of $\left.\mathbf{1 b}\right)$. The solution was then aged ( $4 \mathrm{~s}$ for $1 \mathrm{a}$ and $0.1 \mathrm{~s}$ for $\mathbf{1 b}$ ) to ensure complete oxidation to 2a or b, respectively, which was verified independently from single mixing experiments and the appearance of the diagnostic ligand-to-metal charge transfer (LMCT) feature associated with the $[\mathrm{CuOH}]^{2+}$ core $\left(\lambda_{\max }, \mathrm{nm}\left(\varepsilon, \mathrm{M}^{-1} \mathrm{~cm}^{-1}\right)=548(10000)\right.$ or 500 (13 300) for $\mathbf{2 a}$ or $\mathbf{b}$, respectively). In the subsequent second mixing event, the aged solution of $2 \mathbf{a}$ or $\mathbf{b}$ was combined with a solution of the phenol substrate, and the rapid decay of the LMCT band of $\mathbf{2 a}$ or $\mathbf{b}$ was monitored.

Reactions with phenols ${ }^{\mathrm{X}} \mathrm{ArOH}$ with $\mathrm{X}=\mathrm{NMe}_{2}$, OMe, Me, $\mathrm{H}$, and $\mathbf{C l}$. For the reactions starting with $\mathbf{2 a}$, both stoichiometric (1 eq. of ${ }^{\mathrm{x}} \mathrm{ArOH}$ relative to $2 \mathrm{a}$ ) and pseudo first-order conditions (5-100 eq. of ${ }^{\mathrm{X}} \mathrm{ArOH}$ relative to 2a) were used, except in the case for ${ }^{\mathrm{NMe}_{2}} \mathrm{ArOH}$, the reactions with which were exceptionally fast and could be monitored only under stoichiometric conditions. Most of the reactions of phenols with compound $\mathbf{2 b}$ were too rapid to be measured with excess substrate, so they were measured under stoichiometric conditions. Representative UVvis spectra as a function of time are shown in Fig. 1. For the pseudo first-order reactions performed with excess substrate, decay traces of the absorbance at a single wavelength $(548 \mathrm{~nm})$ 


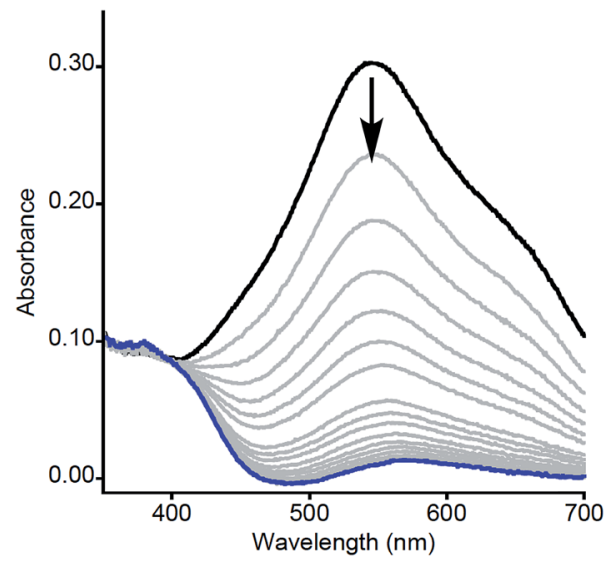

Fig. 1 Representative UV-vis spectra as a function of time ( $1 \mathrm{~ms}$ to $5 \mathrm{~s}$ ) for the reaction of $2 \mathrm{a}$ with ${ }^{\mathrm{Me}} \mathrm{ArOH}$ (5 equiv.) at $-80{ }^{\circ} \mathrm{C}$ in THF. Only selected data shown here for clarity; all data are shown in Fig. S1. $\dagger$

generally fit well to a single exponential decay function, consistent with a first-order decay process involving a single kinetic step (Fig. S1 $\dagger$ ). These results were corroborated by multiwavelength global analysis, ${ }^{10}$ which yielded $k_{\text {obs }}$ values in excellent agreement with those determined by the singlewavelength analysis (within $10 \%$ deviation). Plots of $k_{\text {obs }}$ versus $\left[{ }^{\mathrm{x}} \mathrm{ArOH}\right]_{0}$ were then fit to a linear regression, revealing an excellent linear dependence, and the slopes of these fits were taken as the second-order rate constants $(k)$ for the reactions (Table S1, Fig. S2-S4†). For the stoichiometric (1:1) runs, $k$ values were determined using the method of initial rates. The initial $5-10 \%$ of each concentration $v s$. time profile was fit by linear regression analysis to obtain an initial reaction rate, which was then divided by the square of the initial concentration of the copper complex to obtain the second-order rate constant (Table S2, Fig. S5-S7, and eqn (S3) †). In all cases, these rate constants obtained for reactions with 2 a were within error of those obtained from the pseudo first-order experiments described above, lending credence to the use of this method for all of the reactions of $\mathbf{2 b}$. Average values of the rate constants are summarized in Table 2.

Based on the related reactivity with $\mathrm{C}-\mathrm{H}$ bonds, ${ }^{2 b, c}$ the reactions of $2 \mathbf{a}$ and $\mathbf{b}$ with phenols ${ }^{\mathrm{X}} \mathrm{ArOH}\left(\mathrm{X}=\mathrm{NMe}_{2}, \mathrm{OMe}, \mathrm{Me}, \mathrm{H}\right.$, and $\mathrm{Cl}$ ) very likely yield the respective phenoxyl radicals, ${ }^{\mathbf{1 1}}$ which would be expected to undergo subsequent radical coupling reactions. Attempts to identify such products from batch reactions were only successful in the case of the reactions of $2 \mathrm{a}$ and b with ${ }^{\mathrm{Me}} \mathrm{ArOH}$; Pummerer's ketone ${ }^{12}$ was identified by GC/MS in approximately 35 and 16\% yield, respectively (Scheme 3; see ESI for details $\dagger$ ). We can only speculate that our inability to identify radical coupling products from the reactions with the other phenols is due to their decay via a variety of pathways, as has been suggested in related studies. ${ }^{13}$ Further corroboration of phenoxyl radical generation came from EPR spectroscopic analysis of the product mixtures after reaction of TEMPOH and 2,4,6-tri-t-butylphenol with $2 \mathbf{a}$ and $\mathbf{b}$; signals due to the respective nitroxyl and phenoxyl radicals were observed (Fig. S8†). Quantification of the latter by UV-vis spectroscopy
Table 2 Second order rate constants $(k)$ for the reactions of $2 a$ and b with ${ }^{\times} \mathrm{ArOH}$ at $-80^{\circ} \mathrm{C}^{a}$

\begin{tabular}{lll}
\hline $\mathrm{X}$ & $\mathbf{2 a}(\mathrm{THF})^{b}$ & 2b $(\mathrm{THF})^{c}$ \\
\hline $\mathrm{NMe}_{2}$ & $(1.9 \pm 0.3) \times 10^{6 c}$ & $(6.7 \pm 1.0) \times 10^{6}$ \\
$\mathrm{OMe}$ & $(3.0 \pm 0.5) \times 10^{5}$ & $(1.8 \pm 0.3) \times 10^{6}$ \\
$\mathrm{Me}$ & $(8.9 \pm 1.3) \times 10^{3}$ & $(1.0 \pm 0.2) \times 10^{6}$ \\
$\mathrm{H}$ & $(3.9 \pm 0.6) \times 10^{2}$ & $(1.8 \pm 0.3) \times 10^{5}$ \\
$\mathrm{Cl}$ & $(6.5 \pm 1.0) \times 10^{2}$ & $(1.4 \pm 0.2) \times 10^{5}$ \\
$\mathrm{NO}_{2}$ & $(2.6 \pm 0.4) \times 10^{2 d}$ & $(8.2 \pm 2.6) \times 10^{2}$ \\
$\mathrm{CF}_{3}$ & $(3.0 \pm 0.5) \times 10^{1 d}$ & $(3.0 \pm 1.5) \times 10^{2}$
\end{tabular}

${ }^{a}$ All values in units $\mathrm{M}^{-1} \mathrm{~s}^{-1}$. In all cases, uncertainties are taken as $15 \%$ (resulting from the propagation of maximum possible errors of $10 \%$ each for the concentrations of the two compounds) or as the standard error, whichever is greater. ${ }^{b}$ Values determined from the pseudo-first order analysis for all reactions except for that for $\mathrm{X}=\mathrm{NMe}_{2}$, in which case the rate constant from the stoichiometric analysis was used. See text for details. ${ }^{c}$ Determined from the method of initial rates for $\mathrm{X}=$ $\mathrm{NMe}_{2}, \mathrm{OMe}, \mathrm{Me}, \mathrm{H}$, and $\mathrm{Cl}$; for $\mathrm{X}=\mathrm{NO}_{2}$ and $\mathrm{CF}_{3}$, determined from the mixed first- and second-order fits (eqn (S6) see ESI). See text for details. ${ }^{d}$ Determined from single-wavelength analysis. See text for details.

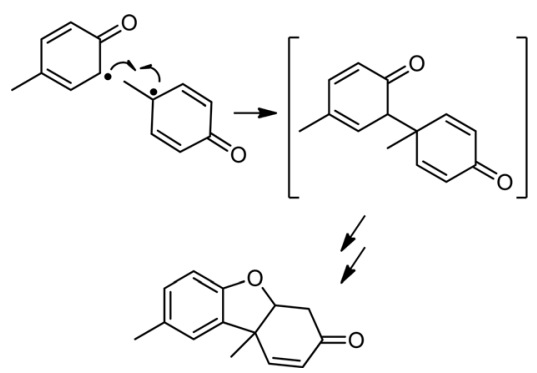

Scheme 3 Formation of Pummerer's ketone from ortho-para coupling of two $p$-cresol phenoxyl radicals (only one resonance form of each of the reacting radicals is shown).

indicated an $\sim 80 \%$ yield for reaction with 2 a (Fig. S9†). ${ }^{\mathbf{1 4}}$ Additionally, the inorganic decay product in all of the reactions with 2a, except in the case of ${ }^{\mathrm{NMe}_{2}} \mathrm{ArOH}$, is the corresponding copper(II)-THF adduct formed as a result of ligand exchange of the coordinated water in $\mathbf{3 a}$ with the THF solvent. This phenomenon has been described in detail previously ${ }^{2 b}$ and is further corroborated in these cases by comparison with the UVvis absorption features of the copper(II)-THF adduct (Fig. S10 $\dagger$ ). The UV-vis decay spectra for reactions with $\mathbf{2 b}$ are distinct from any of the known complexes with this ligand and we can only speculate that the product mixtures for these reactions likely contain some mixture of $\mathrm{LCu}(\mathrm{S})$ species, where $\mathrm{S}=\mathrm{H}_{2} \mathrm{O}$, THF, or ${ }^{\mathrm{x}} \mathrm{ArOH}$. In the case of reactions between $\mathbf{2 a} / \mathbf{b}$ and ${ }^{\mathrm{NMe}_{2}} \mathrm{ArOH}$, the final decay spectra are distinctly different from those of the other phenols in that there is a charge transfer feature in the NIR region (Fig. S11 $\dagger$ ). This feature is stable at $-80{ }^{\circ} \mathrm{C}$, and in the case of reactions with $\mathbf{2 b}$, even persists to some extent after sitting at room temperature overnight. While the identity of this species is under further investigation, we tentatively assign it as some sort of copper-based phenoxyl adduct on the basis of previous reports of similar copper(II)-phenoxyl complexes ${ }^{\mathbf{1 5}}$ and 
the known enhanced stability of the ${ }^{\mathrm{NMe}_{2}} \mathrm{ArO}^{\bullet}$ phenoxyl radical in comparison to the other phenoxyl radicals. ${ }^{\mathbf{1 6}}$

Reactions with phenols ${ }^{\mathrm{X}} \mathrm{ArOH}$ with $\mathrm{X}=\mathrm{NO}_{2}$ and $\mathbf{C F}_{3}$. The reactions of $2 \mathbf{a}$ and $\mathbf{b}$ with ${ }^{\mathrm{CF}_{3}} \mathrm{ArOH}$ and ${ }^{\mathrm{NO}_{2}} \mathrm{ArOH}$ differed from those with the other phenols with respect to kinetic behavior and product(s). For reactions of 2a with ${ }^{\mathrm{CF}_{3}} \mathrm{ArOH}$ and ${ }^{\mathrm{NO}_{2}} \mathrm{ArOH}$ under pseudo-first order conditions (excess substrate), satisfactory single exponential fits could be obtained for the decay traces at $548 \mathrm{~nm}$. Plotting $k_{\mathrm{obs}}$ vs. $\left[{ }^{\mathrm{X}} \mathrm{ArOH}\right]_{0}$ revealed a linear dependence that enabled determination of the second order rate constant (Fig. S $2 \dagger$ ). In addition, however, in the reaction with ${ }^{\mathrm{NO}_{2}} \mathrm{ArOH}$ a new feature at $400 \mathrm{~nm}$ appeared concomitant with the decay of the LMCT feature for 2a at $548 \mathrm{~nm}$ (Fig. 2). Single-wavelength analysis of the growth of the $400 \mathrm{~nm}$ feature revealed a second-order rate constant identical to that for the decay of $2 \mathrm{a}$ (Fig. S12 $\dagger$ ). Thus, we assign the species giving rise to the $400 \mathrm{~nm}$ band as a reaction product that forms at the same rate as consumption of $\mathbf{2 a}$. We tentatively assign the reaction product as the phenolate $\left({ }^{\mathrm{NO}_{2}} \mathrm{ArO}^{-}\right)$on the basis of the close similarity of the $400 \mathrm{~nm}$ feature to that independently measured for a sample of $\left(\mathrm{Bu}_{4} \mathrm{~N}\right)\left({ }^{\mathrm{NO}_{2}} \mathrm{ArO}\right)$ dissolved in THF (Fig. S13 $\dagger$ ), and approximate the yield of ${ }^{\mathrm{NO}_{2}} \mathrm{ArO}^{-}$to be $\sim 55 \%$ with respect to the starting copper concentration. ${ }^{17}$ We suspect that this product is also formed upon reaction of $2 \mathbf{b}$ with ${ }^{\mathrm{NO}_{2}} \mathrm{ArOH}$, albeit in a much smaller amount, but were unable to verify this because of overlapping features in the UV-vis spectra that obfuscated the $400 \mathrm{~nm}$ band (Fig. S14†). ${ }^{18}$ Given the observation of ${ }^{\mathrm{NO}_{2}} \mathrm{ArO}^{-}$as a product, we suspected a possible contribution from a more complicated kinetic model for the reaction of $2 \mathrm{a}$ with ${ }^{\mathrm{NO}_{2}} \mathrm{ArOH}$ that might become evident using multicomponent global analyses. Indeed, the full UV-vis kinetic data for the reactions of 2a with ${ }^{{ }^{\mathrm{NO}_{2}}} \mathrm{ArOH}$ and ${ }^{\mathrm{CF}_{3}} \mathrm{ArOH}$ could be satisfactorily fit using multicomponent analyses to a stepwise kinetic model involving the formation of an intermediate $(\mathrm{A} \rightarrow \mathrm{B} \rightarrow \mathrm{C})$ (Fig. S15-S18 $\dagger$ ). This fit is statistically improved relative to the simpler singlestep fit applicable to the reactions of the other phenol substrates, supporting differing mechanisms. We address this issue in further detail below.

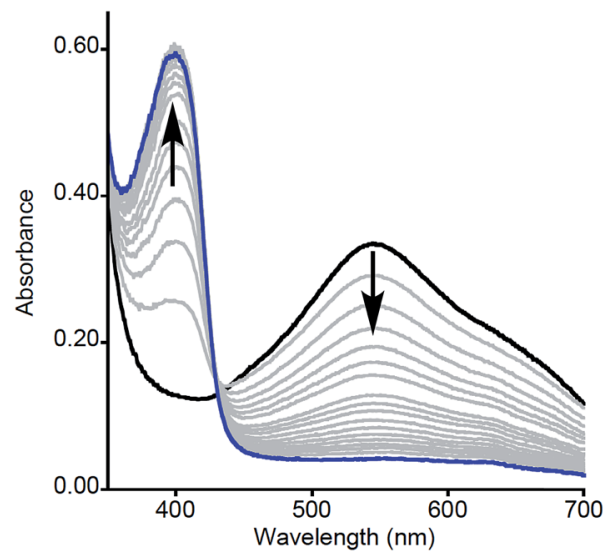

Fig. 2 Representative UV-vis spectra as a function of time (1 ms to 100 s) for the reaction of $2 a$ (prepared by reaction of $1 \mathrm{a}$ with $[\mathrm{Fc}]\left[\mathrm{BAr}_{4}\right]$ ) with ${ }^{\mathrm{NO}} 2 \mathrm{ArOH}$ (5 equiv.). Only selected data shown for clarity.
For reactions of 2a with ${ }^{\mathrm{CF}_{3}} \mathrm{ArOH}$ and ${ }^{\mathrm{NO}_{2}} \mathrm{ArOH}$ under stoichiometric conditions (equimolar reactant and substrate), competing reaction of $2 \mathrm{a}$ with solvent THF complicated the analysis. Thus, while satisfactory fits to the single wavelength data for these reactions could be obtained using the initial rates method, we observed that the second order rate constant from this analysis was significantly higher than that obtained from the pseudo-first order analysis described above. We hypothesized that the rate of decay of $2 \mathbf{a}$ in the stoichiometric reactions was enhanced by an added component: attack at the $\mathrm{C}-\mathrm{H}$ bonds of THF (a phenomenon described previously). ${ }^{2 b, 19}$ Equations that model this additional pathway by incorporating an added first-order self-decay component were used to fit the data (eqn $(\mathrm{S} 6) \dagger)$. These fits yielded second-order rate constants in good agreement with those determined from the pseudo-first order analyses above (Fig. S19 and S20 $\dagger$ ), thus validating the model that includes the self-decay (THF attack) process. Additionally, the rates of THF activation obtained from these fits are in good agreement with the independently measured self-decay rates of 2a and $\mathbf{b}$ in THF, which further corroborates the use of this additional kinetic pathway.

As in the case of the more electron rich phenols discussed above, distinct phenolic oxidation products, including the expected $\mathrm{C}-\mathrm{C}$ coupled species, could not be identified in the product mixtures for the reactions with either $2 \mathbf{a}$ or $\mathbf{b}$. Again, this is likely due to a variety of complicated decay pathways, which is further convoluted in these cases owing to comparable rates of self-decay for $\mathbf{2 a}$ or $\mathbf{b}$. However, in contrast to reactions with the more electron rich derivatives, reactions of ${ }^{\mathrm{NO}_{2}} \mathrm{ArOH}$ and ${ }^{\mathrm{CF}_{3}} \mathrm{ArOH}$ gave final UV-vis spectra distinct from that of the $\mathrm{LCu}(\mathrm{THF})$ species as described before and shown in Fig. S10. $\dagger$ We attribute this difference to the potential formation of other copper(II)-based products in these cases, such as, for example, copper(II)-phenoxide/phenol adducts. More interestingly, for the reactions of both substrates with $\mathbf{2 a}$, a conspicuous absorption feature is observed in the approximate range of 625$630 \mathrm{~nm}$. This absorption feature is in good agreement with that for $\mathrm{Fc}^{+}\left(\lambda_{\max }(\varepsilon)=623 \mathrm{~nm}\left(1000 \mathrm{M}^{-1} \mathrm{~cm}^{-1}\right)\right.$; see Fig. S21 and $\mathrm{S} 22 \dagger)$, the oxidant used to generate $2 \mathrm{a}$ from 1a. This curious observation suggests that $\mathrm{Fc}^{+}$is somehow regenerated in these reactions. We evaluate the implications of these observations in the discussion section below.

Particularly intriguing was the putative formation of ${ }^{\mathrm{NO}_{2}} \mathrm{ArO}^{-}$ as a product of the reaction between $2 \mathbf{a}$ and ${ }^{\mathrm{NO}_{2}} \mathrm{ArOH}$, and we sought to investigate this further. One possible pathway for phenolate formation could be the reduction of ${ }^{{ }^{N O}}{ }^{2} \mathrm{ArO}^{*}$ by ferrocene, present in solution from the initial oxidation of 1a. However, the potential involvement of an intermediate as suggested from kinetic modeling led us to pursue the alternate possibility of phenolate formation from the deprotonation of ${ }^{\mathrm{NO}_{2}} \mathrm{ArOH}$ by $2 \mathrm{a}$, which would generate a $\left[\mathrm{LCuOH}_{2}\right]^{+}$species (4a) that could also be reduced by the ferrocene present in the reaction mixture (to yield $\mathrm{Fc}^{+}$). Indeed, the feature at $\sim 625 \mathrm{~nm}$ in the product UV-vis spectrum of this reaction, as well as signals in the product EPR spectrum at $g=4.32,2.04$, and 1.54, corroborate the presence of $\mathrm{Fc}^{+}$(Fig. S22 $\dagger$ ). ${ }^{20}$ Attempts to quantify the $\mathrm{Fc}^{+}$under these dilute reaction conditions were 
complicated by the presence of overlapping features; however, analysis of product mixtures for reactions run at higher concentrations $\left(\left[\mathrm{LCu}{ }^{\mathrm{III}} \mathrm{OH}\right]_{0}=0.5 \mathrm{mM}\right)$ indicate that approximately $90 \%$ of the $\mathrm{Fc}^{+}$is recovered (see Fig. S23†). To further probe these hypotheses, we repeated the reactions using stronger oxidants, namely tri- $p$-tolylamminium radical-cation $\left[(p \text {-tolyl })_{3} \mathrm{~N}^{+\cdot}\right]\left(E_{1 / 2}=0.38 \mathrm{~V}\right.$ vs. $\left.\mathrm{Fc}^{+} / \mathrm{Fc}\right)$ and thianthrenium radical cation $\left[\mathrm{C}_{12} \mathrm{H}_{8} \mathrm{~S}_{2}^{+\cdot}\right]\left(E_{1 / 2}=0.86 \mathrm{~V} v s . \mathrm{Fc}^{+} / \mathrm{Fc}\right)$, the reduced forms of which would not be able to reduce the formed phenoxyl radical or 4a. Treatment of a THF solution of $1 \mathrm{a}$ with 1 eq. of $\left[(p \text {-tolyl })_{3} \mathrm{~N}\right] \mathrm{PF}_{6}$ or $\left[\mathrm{C}_{12} \mathrm{H}_{8} \mathrm{~S}_{2}\right] \mathrm{PF}_{6}$ (dissolved in acetonitrile for solubility/stability purposes) at $-80^{\circ} \mathrm{C}$ led to the growth of the typical feature at $548 \mathrm{~nm}$ associated with formation of $2 \mathrm{a}$ (Fig. 3 , black spectrum). Upon addition of ${ }^{\mathrm{NO}_{2}} \mathrm{ArOH}$ (5 equiv.) to this solution, the absorption feature at $400 \mathrm{~nm}$ associated with ${ }^{\mathrm{NO}_{2}} \mathrm{ArO}^{-}$still appeared and the characteristic LMCT feature for 2a decreased in intensity and shifted slightly $\left(\lambda_{\max }=550 \mathrm{~nm}\right.$, Fig. 3, blue spectrum). This spectroscopic feature was stable for minutes upon standing at $-80{ }^{\circ} \mathrm{C}$, but bleached upon warming to room temperature (Fig. 3, red spectrum), consistent with it being associated with a reactive intermediate. It is noteworthy that the feature at $400 \mathrm{~nm}$ is lower in intensity when compared to the experiments using $\mathrm{Fc}^{+}$as the oxidant; the yield of ${ }^{\mathrm{NO}_{2}} \mathrm{ArO}^{-}$ can be approximated to be $\sim 30 \%$ with respect to the starting copper concentration. Taken together, all of these observations support the hypothesis that the reduced ferrocene, present in the reaction mixture (from the initial oxidation of 1a) is involved in subsequent reactions.

Additional experiments were performed to further evaluate the nature of the intermediate involved in the reaction of $\mathbf{2 a}$ with ${ }^{\mathrm{NO}_{2}} \mathrm{ArOH}$. To test for the feasibility of the intermediacy of $4 \mathbf{a}$, a solution of $2 \mathbf{a}$ (generated by reaction of $1 \mathbf{a}$ with $\left[\mathrm{C}_{12} \mathrm{H}_{8} \mathrm{~S}_{2}\right]$ $\mathrm{PF}_{6}$ in THF at $-80^{\circ} \mathrm{C}$ ) was treated with the weak acid 2,4,6-trimethylpyridnium triflate (Fig. S24, left†). The resulting UV-vis spectrum was similar to that shown in Fig. 3 (blue). An analogous spectrum was also obtained upon reaction of $\mathrm{LCu}(\mathrm{THF})$

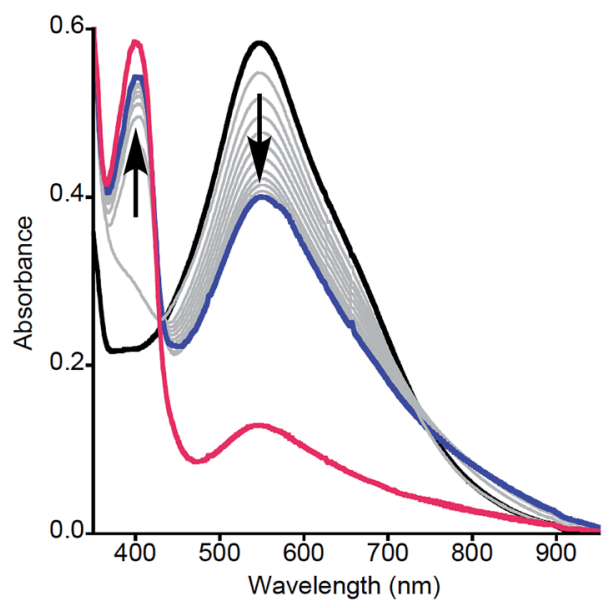

Fig. 3 UV-vis spectra for the reaction of $2 a$ (prepared by reaction of $1 a$ with $(p \text {-tolyl })_{3} \mathrm{~N}^{+\cdot}$ ) with ${ }^{\mathrm{NO}}{ }_{2} \mathrm{ArOH}$ in $\mathrm{THF}$ at $-80{ }^{\circ} \mathrm{C}$. (Black) Initial spectrum of 2a. (Grey) Intermediate spectra as a function of time (4834 s). (Blue) Final spectrum stable at $-80^{\circ} \mathrm{C}$. (Red) Spectrum resulting from warming to room temperature. dissolved in wet acetone or THF (conditions known to yield 3a) ${ }^{2}$ with $\left[\mathrm{C}_{12} \mathrm{H}_{8} \mathrm{~S}_{2}\right] \mathrm{PF}_{6}$ at $-80^{\circ} \mathrm{C}$ (Fig. S24, right and Fig. S28, right $\dagger$ ), again consistent with the intermediate being 4a. Alternatively, it is possible that $[\mathrm{LCu}(\mathrm{THF})]^{+}$, formed as a result of a ligand exchange with the solvent, could be present in the above reactions. To evaluate this possibility, we reacted $\mathrm{LCu}(\mathrm{THF})$ in anhydrous THF with $\left[\mathrm{C}_{12} \mathrm{H}_{8} \mathrm{~S}_{2}\right] \mathrm{PF}_{6}$ at $-80{ }^{\circ} \mathrm{C}$. In this case, however, the UV-vis spectrum of the resulting solution differed significantly from that in Fig. 3 (Fig. S25; $\dagger$ the identity of this new species is currently under investigation). A third possibility is that the intermediate is the complex $\mathrm{LCu}\left({ }^{\mathrm{NO}_{2}} \mathrm{ArO}\right)$, formed by ligand exchange with ${ }^{\mathrm{NO}_{2}} \mathrm{ArO}^{-}$. To evaluate this hypothesis, we prepared $\left(\mathrm{Bu}_{4} \mathrm{~N}\right)\left[\mathrm{LCu}\left({ }^{\mathrm{NO}_{2}} \mathrm{ArO}\right)\right]$ independently, characterized it fully (including by X-ray crystallography; Fig. S26 $\dagger$ ), and treated a solution of it in THF with $\left[(p \text {-tolyl })_{3} \mathrm{~N}\right] \mathrm{PF}_{6}$ at $-80{ }^{\circ} \mathrm{C}$. The results ruled out $\mathrm{LCu}\left({ }^{\mathrm{NO}_{2}} \mathrm{OAr}\right)$ as the intermediate, as the UV-vis spectrum of the resulting solution also differed from that shown in Fig. 3 (Fig. S27; $†$ the identity of this oxidized species is also under investigation).

\section{Discussion}

\section{Kinetics data and control experiments}

Second order rate constants for the reactions of the copper(III)hydroxide complexes $\mathbf{2 a} / \mathbf{b}$ with a range of phenols were determined using low temperature stopped-flow methods (Table 2). With the same phenol, $k$ values for reactions of $2 \mathbf{b}$ were $3.5-460$ times greater than those of $\mathbf{2 a}$. Significant rate differences were previously observed for reactions of $2 \mathbf{a}$ and $\mathbf{b}$ with $\mathbf{C}-\mathrm{H}$ bonds, and were attributed to the higher $\mathrm{BDE}$ for the $\mathrm{O}-\mathrm{H}$ bond formed in the product copper(II)-aqua complex $\mathbf{3 b}$ compared to that of 3a. ${ }^{2 c}$ For each complex, $k$ values over the range of phenols were found to vary by $4-5$ orders of magnitude as a function of parasubstituents (Table 2) and for runs with the more electron-rich phenols ( $\mathrm{X}=\mathrm{NMe}_{2}, \mathrm{OMe}, \mathrm{Me}, \mathrm{H}$, and $\mathrm{Cl}$ ), the data fit well to a kinetic model involving a single-step $(\mathrm{A} \rightarrow \mathrm{B})$.

However, the data obtained for reactions between $2 \mathrm{a}$ and the most electron-deficient phenols $\left(\mathrm{X}=\mathrm{NO}_{2}, \mathrm{CF}_{3}\right)$ were more accurately modelled using a mechanism involving an intermediate species $(\mathrm{A} \rightarrow \mathrm{B} \rightarrow \mathrm{C})$. Coupled with the clear observation of ${ }^{\mathrm{NO}_{2}} \mathrm{ArO}^{-}$as a product in reactions between 2a and ${ }^{\mathrm{NO}_{2}} \mathrm{ArOH}$, these results suggest a more complicated pathway compared to what was seen for the more electron-rich phenols. To rationalize the production of ${ }^{\mathrm{NO}_{2}} \mathrm{ArO}^{-}$, we considered several possible mechanisms (Scheme 4). Initial HAT (i.e., CPET) could yield the copper(II)-aqua complex 3a and the phenoxyl radical ${ }^{\mathrm{NO}_{2}} \mathrm{ArO}{ }^{\cdot}$ ("HAT" in Scheme 4). This radical might then undergo reduction by ferrocene (formed in the initial reaction used to generate the reactant 2a) to produce ${ }^{\mathrm{NO}_{2}} \mathrm{ArO}^{-}$and $\mathrm{Fc}^{+}$. Alternatively, 3a and ${ }^{\mathrm{NO}_{2}} \mathrm{ArO}$ might participate in a redox equilibrium to yield the copper(III)-aqua complex $4 \mathbf{a}$ and ${ }^{\mathrm{NO}_{2}} \mathrm{ArO}^{-}$("ET"). While, such an equilibrium seems plausible given the very close $E_{1 / 2}$ values for the ${ }^{\mathrm{NO}_{2}} \mathrm{ArO}{ }^{*} / \mathrm{NO}_{2} \mathrm{ArO}^{-}\left(0.314 \mathrm{~V} \text { vs. } \mathrm{Fc}^{+} / \mathrm{Fc}\right)^{8}$ and $\mathrm{Cu}^{\mathrm{III}} / \mathrm{Cu}^{\mathrm{II}}$ couples for the copper(III)-aqua species $\left(0.345 \mathrm{~V} v s\right.$. $\left.\mathrm{Fc}^{+} / \mathrm{Fc}\right){ }^{2 b}$ it is likely that alternate decay pathways for the highly reactive phenoxyl radical ${ }^{21}$ will drive this equilibrium to the right, and thus the equilibrium concentrations of $\mathbf{4 a}$ and ${ }^{\mathrm{NO}_{2}} \mathrm{ArO}^{-}$should 


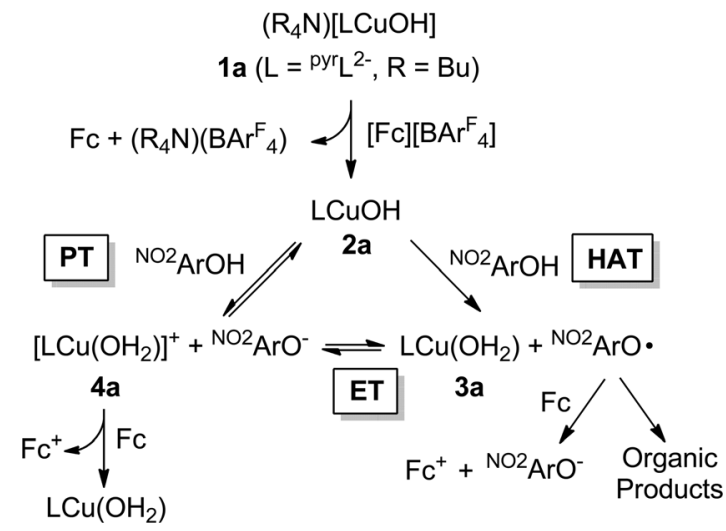

Scheme 4 Mechanisms that would yield the phenolate ${ }^{\mathrm{NO}_{2}} \mathrm{ArO}^{-}$

be miniscule. Alternately, ${ }^{\mathrm{NO}_{2}} \mathrm{ArO}^{-}$could also form via direct proton transfer between 2a and ${ }^{\mathrm{NO}_{2}} \mathrm{ArOH}$ ("PT"). In such a scenario, 4a would now either (a) be reduced by ferrocene present in the reaction mixture or (b) react via the "ET" pathway to form the phenoxyl radical.

Central to several of the above hypotheses is the involvement of the copper(III)-aqua species $\mathbf{4 a}$, which had previously only been implicated in cyclic voltammetry experiments. ${ }^{2 b} \mathrm{We}$ hypothesized that if the quenching of ${ }^{{ }^{N}}{ }_{2} \mathrm{ArO}{ }^{*}$ and/or $4 \mathbf{a}$ by ferrocene could be avoided, we might be able to observe $\mathbf{4 a}$ and thus provide independent evidence in favor of it being a feasible intermediate in the reaction of $2 \mathrm{a}$ with ${ }^{\mathrm{NO}_{2}} \mathrm{ArOH}$. Indeed, an intermediate displaying UV-vis absorption features reminiscent of reported pyridine-dicarboxamido copper(III)-complexes ${ }^{2}$ was observed when oxidants stronger than $\mathrm{Fc}^{+}\left(\right.$e.g. $\left[(p \text {-tolyl })_{3} \mathrm{~N}\right] \mathrm{PF}_{6}$ or $\left.\left[\mathrm{C}_{12} \mathrm{H}_{8} \mathrm{~S}_{2}\right] \mathrm{PF}_{6}\right)$ were used. Additionally, these reactions also yielded ${ }^{\mathrm{NO}_{2}} \mathrm{ArO}^{-}$, albeit in slightly lower yields when compared to the $\mathrm{Fc}^{+}$reactions ( $30 \%$ versus $55 \%$ ). While the detailed kinetic modeling of these reactions using the stronger oxidants proved complicated, we do note that the observed rate constant $\left(k_{\mathrm{obs}}\right)$ for the growth of the $400 \mathrm{~nm}$ feature is essentially identical when either $\mathrm{Fc}^{+}$or $(\text {tolyl })_{3} \mathrm{~N}^{+\cdot}$ is used as the initial oxidant (Fig. S29†). These observations support the notion that the most plausible intermediate would be $\mathbf{4 a}$ formed via direct proton transfer between 2a and ${ }^{\mathrm{NO}_{2}} \mathrm{ArOH}$. Moreover, a number of control experiments ruled out other reasonable intermediates like $[\mathrm{LCu}(\mathrm{THF})]^{+}$or $\mathrm{LCu}\left({ }^{\mathrm{NO}_{2}} \mathrm{ArO}\right)$, which were considered on the basis of known ligand exchange chemistry of $3 \mathbf{a}^{2 b}$ More importantly, independent experiments aimed at characterizing 4a using UV-vis spectroscopy via either direct oxidation of 3a or protonation of 2a, yielded a charge-transfer feature at $\sim 550 \mathrm{~nm}$ closely resembling that observed in the intermediate..$^{22}$ It is also noteworthy that the UV-vis spectrum of the intermediate extracted from the kinetic modelling using multi-component global fitting agrees well with the independent spectra for $\mathbf{4 a}$ (Fig. S28†). We also considered the possibility that this intermediate could be due to the formation of some kind of precursor complex between 2a and ${ }^{\mathrm{NO}_{2}} \mathrm{ArOH}$. Such species have been implicated in a number of transition metal based oxidations of phenols, often as a rationale for observed saturation behavior in these systems. ${ }^{23}$ However, we view this idea to be unlikely on the basis of (a) the formation of ${ }^{\mathrm{NO}_{2}} \mathrm{ArO}^{-}$concomitant with formation of the intermediate, (b) the persistence of the intermediate, and (c) thermodynamic arguments (presented below).

Taken together, the more complex kinetic model required to fit the data and the direct spectroscopic observations of the intermediate in independent reactions supports the feasibility of copper(III)-aqua adduct $\mathbf{4 a}$ as the intermediate in reactions of 2a with ${ }^{\mathrm{NO}_{2}} \mathrm{ArOH}$. This conclusion is not undermined by the fact that when $\mathrm{Fc}^{+}$is used as an oxidant to generate $2 \mathrm{a}$, the spectroscopic features associated with $\mathbf{4 a}$ are not observed upon subsequent reaction with ${ }^{\mathrm{NO}_{2}} \mathrm{ArOH}$; the absence of said features may be rationalized by postulating that $\mathbf{4 a}$ is reduced in situ by ferrocene present in the reaction mixture. This postulate is supported by identification of $\mathrm{Fc}^{+}$in the UV-vis and EPR spectra of the product mixtures and the known reduction potential of the $4 \mathrm{a} / 3 \mathbf{3}$ couple in $\operatorname{THF}\left(E_{1 / 2}=0.345 \mathrm{~V} v s . \mathrm{Fc}^{+} / \mathrm{Fc}\right) .^{2 b}$

Also in favor of an initial proton transfer step being involved for the acidic phenols is the fact that $\mathrm{Fc}^{+}$is regenerated in the reactions between 2a and ${ }^{\mathrm{CF}_{3}} \mathrm{ArOH}$ at high substrate concentrations. Given that the approximate $\mathrm{p} K_{\mathrm{a}}$ difference $\left(\Delta \mathrm{p} K_{\mathrm{a}}\right)$ between $4 \mathrm{a}$ and ${ }^{\mathrm{CF}_{3}} \mathrm{ArOH}$ is 3.5 , proton transfer would be expected to be significant only at high concentrations of ${ }^{\mathrm{CF}_{3}} \mathrm{ArOH}$, consequently leading to the regeneration of $\mathrm{Fc}^{+}$only under such circumstances. It is also noteworthy that control reactions with ${ }^{\mathrm{Me}} \mathrm{ArOH}$ as substrate and using $\left[(p \text {-tolyl })_{3} \mathrm{~N}\right] \mathrm{PF}_{6}$ or $\left[\mathrm{C}_{12} \mathrm{H}_{8} \mathrm{~S}_{2}\right] \mathrm{PF}_{6}$ as the oxidant did not yield any observable intermediate; instead, the features of 2a decayed rapidly as was observed in the stopped-flow studies (Fig. S30†). All the data support the hypothesis that the reactions of $2 \mathrm{a}$ with ${ }^{\mathrm{NO}_{2}} \mathrm{ArOH}$ and ${ }^{\mathrm{CF}_{3}} \mathrm{ArOH}$ proceed through a different mechanism when compared to the other phenols, which is further explored in thermodynamic arguments below.

For the reactions of $\mathbf{2 b}$ with ${ }^{\mathrm{NO}_{2}} \mathrm{ArOH}$, the evidence in favor of a divergent mechanism is less clear. In these reactions, data indicating the formation of ${ }^{\mathrm{NO}_{2}} \mathrm{ArO}^{-}$, regeneration of $\mathrm{AcFc}^{+}$, and the presence of an intermediate are all lacking. The lack of evidence for aqua adduct $\mathbf{4 b}$ may derive from the decreased basicity of $2 \mathbf{b}$ relative to $2 \mathbf{a}\left(\sim 2 \mathrm{p} K_{\mathrm{a}}\right.$ units). ${ }^{2 c}$ This decreased propensity for proton transfer from ${ }^{\mathrm{NO}_{2}} \mathrm{ArOH}$ to $2 \mathbf{b}$ would be offset by a slightly increased thermodynamic driving force for CPET. Thus, while the proton transfer might indeed be induced at higher substrate concentrations (as is suggested for the reaction between 2a and ${ }^{\mathrm{CF}_{3}} \mathrm{ArOH}$ ), its overall contribution in altering the mechanism of the reaction cannot be established unambiguously. Nonetheless, on the basis of the linear free energy plots discussed below, we hypothesize that the reaction between $2 \mathbf{b}$ and ${ }^{\mathrm{NO}_{2}} \mathrm{ArOH}$ might also involve initial proton transfer.

\section{Thermodynamic considerations}

Because the thermodynamic data ( $K_{\mathrm{a}}, E_{1 / 2}$, BDFE) for the phenols were obtained in $\mathrm{DMSO}^{\mathbf{8}, 9}$ (Table 1) and no such data is available in THF (the solvent used to acquire the kinetic data for the reactions of $2 \mathbf{a}$ and $\mathbf{b}$ with the phenols) we sought to convert rate constants measured in THF to the corresponding values in 
DMSO. Solvent effects on HAT reactions from phenols in a variety of solvents have been examined previously, and an empirical equation was developed that correlates the rates of such reactions across different solvents (eqn (1)). ${ }^{24}$ In this equation, (i) $k^{\mathrm{S}}(\mathrm{ArOH} / \mathrm{X})$ denotes the HAT rate constant for reaction of the phenol $(\mathrm{ArOH})$ with a reagent $\mathrm{X}$ in a given solvent $\mathrm{S}$, (ii) $k^{\mathrm{O}}(\mathrm{ArOH} / \mathrm{X})$ denotes the HAT rate constant in an alkane solvent and is unique to the particular reactant pair, (iii) $\beta_{2}^{\mathrm{H}}$ (unique to solvent $\mathrm{S}$ ) represents a general thermodynamically related scale of hydrogen-bond acceptor abilities for different solvents in $\mathrm{CCl}_{4}$, and (iv) $\alpha_{2}^{\mathrm{H}}$ (unique to phenol ArOH) represents a general thermodynamically related scale of phenol hydrogen bond donor strength. Using reported values of $\alpha_{2}^{\mathrm{H}}$ (Table S3 $\dagger$ ) and $\beta_{2}^{\mathrm{H}}$ (0.51 for THF and 0.78 for DMSO), ${ }^{25}$ we subtracted forms of eqn (1) (one for THF and one for DMSO) and included the $\beta_{2}^{\mathrm{H}}$ values to yield eqn (2). The rate constants in $\mathrm{DMSO}^{26}$ were then calculated using eqn (2); these are listed below in Table 3 .

$$
\log \left(k_{\mathrm{ArOH} / \mathrm{X}}^{\mathrm{S}}\right)=\log \left(k_{\mathrm{ArOH} / \mathrm{X}}^{\mathrm{o}}\right)-8.3 \alpha_{2}^{\mathrm{H}} \beta_{2}^{\mathrm{H}}
$$

$$
\log k_{\mathrm{DMSO}}=\log k_{\mathrm{THF}}-2.241 \alpha_{2}^{\mathrm{H}}
$$

Plots of $\log k_{\mathrm{DMSO}}$ versus $\log K, E_{1 / 2}$, and $\mathrm{p} K_{\mathrm{a}}$ are shown in Fig. 4. Here $k$ is the second order rate constant of the reaction in DMSO (from Table 3), $E_{1 / 2}$ is the reduction potential of the ${ }^{\mathrm{x}} \mathrm{ArOH}$ in $\operatorname{DMSO}\left(E_{1 / 2}\left(\mathrm{ROH}^{+} / \mathrm{ROH}\right)\right.$ in Table 1$)$, and $\mathrm{p} K_{\mathrm{a}}$ is for the phenol in DMSO (Table 1). The equilibrium constant $K$ is for the reaction between $\mathbf{2 a}$ or $\mathbf{b}$ with the phenol ${ }^{\mathrm{x}} \mathrm{ArOH}$ to form $3 \mathbf{a}$ or b and the phenoxyl radical ${ }^{\mathrm{x}} \mathrm{ArO}$, and was determined from the approximate $\Delta G_{\mathrm{CPET}}$ (defined as the difference in the bond dissociation free energy for the phenol $\mathrm{O}-\mathrm{H}$ and the BDE of the corresponding copper(II)-aqua complex) at $T=298 \mathrm{~K}$.

The linear correlation between $\log k$ and $\log K$ (Fig. 4a) seems to support a similar mechanism operating across all the phenol substrates. The unitless slope of 0.47 and 0.44 for this Brønsted-type plot shows that an increase of $K_{\mathrm{CPET}}$ of $10^{2}$ gives an increase in $k_{\mathrm{CPET}}$ of roughly 10 , with the value of roughly $1 / 2$ being consistent with a relationship between driving force and

Table 3 Second order rate constants $(k)$ for the reactions of $2 \mathrm{a}$ and b with ${ }^{\times} \mathrm{ArOH}$ at $-80{ }^{\circ} \mathrm{C}$, converted from THF to DMSO ${ }^{a}$

\begin{tabular}{lll}
\hline $\mathrm{X}$ & $\mathbf{2 a}(\mathrm{DMSO})^{b}$ & 2b (DMSO) \\
\hline $\mathrm{NMe}_{2}$ & $1.0 \times 10^{5}$ & $3.5 \times 10^{5}$ \\
$\mathrm{OMe}$ & $1.6 \times 10^{4}$ & $9.4 \times 10^{4}$ \\
$\mathrm{Me}$ & $4.7 \times 10^{2}$ & $5.3 \times 10^{4}$ \\
$\mathrm{H}$ & $1.8 \times 10^{1}$ & $8.3 \times 10^{3}$ \\
$\mathrm{Cl}$ & $2.0 \times 10^{1}$ & $4.4 \times 10^{3}$ \\
$\mathrm{NO}_{2}$ & $4.5 \times 10^{0}$ & $1.4 \times 10^{1}$ \\
$\mathrm{CF}_{3}$ & $7.2 \times 10^{-1}$ & $7.0 \times 10^{0}$
\end{tabular}

${ }^{a}$ All values in units $\mathrm{M}^{-1} \mathrm{~s}^{-1} .{ }^{b}$ Estimated from the experimental values in THF (Table 2) using an empirical correlation of phenol rate constants with solvent hydrogen bonding properties (eqn (1) and (2); see text). Given that the uncertainties in $\alpha$ and $\beta$ are unknown, no uncertainties are reported for the DMSO values. kinetic barrier that is within the typical low-driving force Marcus regime $\left(\Delta G^{\circ} \ll 2 \lambda\right)$ and is in line with what has been observed for other cases of PCET. ${ }^{24 d, 27}$ The plots of $\log k v s$. $E_{1 / 2}\left({ }^{\mathrm{X}} \mathrm{ArOH}^{+} \cdot{ }^{\mathrm{x}} \mathrm{ArOH}\right)$ (Fig. $\left.4 \mathrm{~b}\right)$ may also be fit to straight lines, although the fits are of lower quality, with slopes of $-2.5 \mathrm{~V}^{-1}$ $\left(R^{2}=0.84\right)$ and $-2.1 \mathrm{~V}^{-1}\left(R^{2}=0.76\right)$. Converting from relative reduction potentials to relative equilibrium constants for ET

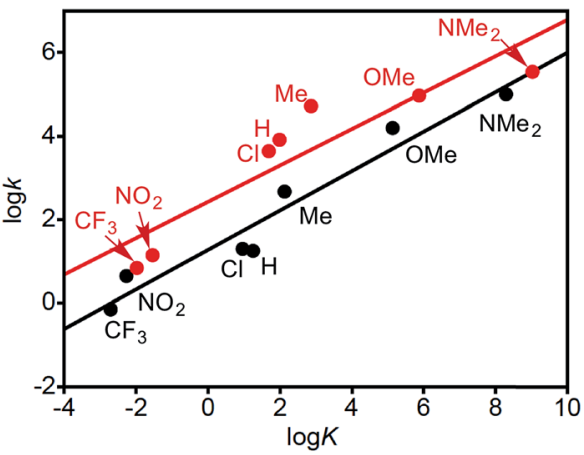

(a)

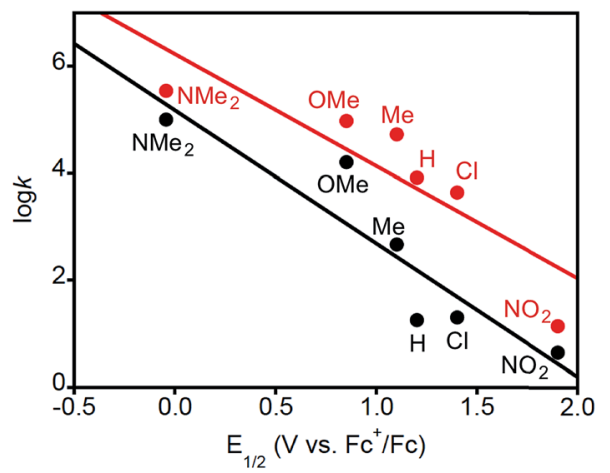

(b)

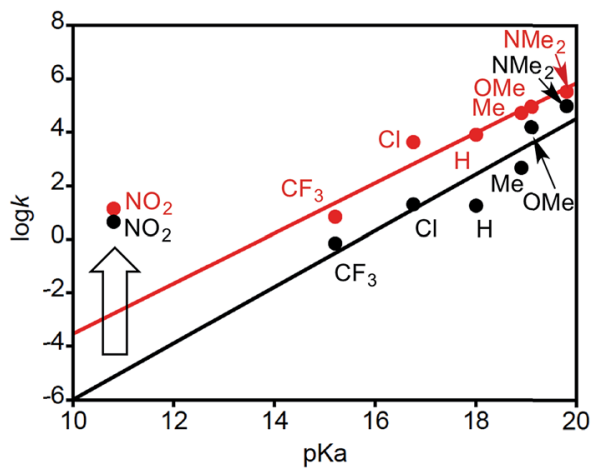

(c)

Fig. 4 (a) Plots of log $k_{\mathrm{DMSO}} v$ s. $\log K_{\mathrm{CPET}}$ for reactions of $2 \mathrm{a}$ (black) and $2 \mathrm{~b}$ (red) with phenols ${ }^{\times} \mathrm{ArOH}$ (X labeled). Linear fits have slopes of 0.47 $\left(R^{2}=0.94\right)$ and $0.44\left(R^{2}=0.84\right)$, respectively. (b) Plots of log $k_{\mathrm{DMSO}} v \mathrm{~s}$. $E_{1 / 2}\left({ }^{\mathrm{X}} \mathrm{ArOH}^{+} \cdot /{ }^{\mathrm{X}} \mathrm{ArOH}\right)(\mathrm{X}$ indicated) for their reactions with $2 \mathrm{a}$ (black) and $2 \mathrm{~b}$ (red). The point for ${ }^{\mathrm{CF}_{3}} \mathrm{ArOH}$ is not included as the corresponding $E_{1 / 2}$ is not known. Linear fits have slopes of $-2.5\left(R^{2}=0.84\right)$ and $-2.1\left(R^{2}=0.76\right)$, respectively. (c) Plots of log $k_{\mathrm{DMsO}} v s$. $\mathrm{p} K_{\mathrm{a}}$ of the phenols ${ }^{X} \mathrm{ArOH}$ (X indicated) for their reactions with $2 \mathrm{a}$ (black) and $2 \mathrm{~b}$ (red). Linear fits do not include the data points for $\mathrm{X}=\mathrm{NO}_{2}$ and have slopes of $1.1\left(R^{2}=0.85\right)$ and $0.94\left(R^{2}=0.93\right)$, respectively. The wide arrow indicates the $\mathrm{X}=\mathrm{NO}_{2}$ outliers. 
from ${ }^{\mathrm{X}} \mathrm{ArOH}$ to $\mathbf{2 a}$ or $\mathbf{b}$ (alternately viewed as slopes of the linear fits to $(R T / F) \ln k v s$. $E_{1 / 2}$ plots, as depicted in Fig. S31 $\dagger$ ) gives respective unitless slopes of 0.17 and 0.12 , which reflect that these reactions are not very sensitive to the reduction potential of the phenols. The slope of the plot of $\log k v s$. phenol $\mathrm{p} K_{\mathrm{a}}$ (Fig. 4c, with linearity only achieved by omitting the data point for $\mathrm{X}=\mathrm{NO}_{2}$ ) is unusual. Even though the reactions involve removal of the phenolic proton, the more acidic phenols in general react slower. For example, ${ }^{\mathrm{NMe}_{2}} \mathrm{ArOH}$ is 3 orders of magnitude less acidic than ${ }^{\mathrm{Cl}} \mathrm{ArOH}$, but it reacts 5000 and 800 times faster for $\mathbf{2 a}$ and $\mathbf{b}$, respectively. Thus the Brønsted plot has a positive slope, of 1.1. This rules out an initial protontransfer step for these phenols, as this would have more acidic phenols reacting faster. The points for $\mathrm{X}=\mathrm{NO}_{2}$ are anomalous in the plots of $\log k v s$. $\mathrm{p} K_{\mathrm{a}}$ (Fig. 4c). The rate constants for reactions with this phenol are significantly faster-by $>4$ orders of magnitude-than that predicted by the linear dependence displayed by the other substrates. Interestingly, and in contrast to what we observe, in the case of other examples for which a consistent CPET mechanism was established, plots of log $k v s$. $\mathrm{p} K_{\mathrm{a}}, E_{1 / 2}$, and BDFE all displayed good linear correlations across all substrates. ${ }^{13,28}$

We interpret the data presented in Fig. 4 to indicate that while a common CPET mechanism is followed by most of the phenols, for the most acidic phenol with $\mathrm{X}=\mathrm{NO}_{2}$, initial proton transfer followed by a subsequent electron transfer (PT/ET) likely occurs competitively with the CPET pathway. ${ }^{6 c, 29}$ The observation of the aquo complex $\mathbf{4 a}$ as an intermediate shows that CPET is not the only process occurring for this phenol. Still, the fact that the rate constant for the reaction shows a good linear correlation with the driving force for a CPET reaction (Fig. 4a) is intriguing and suggests that the reaction likely proceeds by both pathways at similar rates. Detailed kinetic modeling is complicated by the involvement of the reduced form of the initial ferrocenium oxidant, with some of the phenoxyl radical apparently generated via a CPET mechanism being reduced by $\mathrm{Fc}$, thus increasing the apparent yield of the phenolate. The higher yields of ${ }^{\mathrm{NO}_{2}} \mathrm{ArO}^{-}$when $\mathrm{Fc}^{+}$is used as an oxidant are consistent with this notion. For the stronger oxidants however, any phenolate formed is probably from the initial PT pathway in the PT/ET mechanism.

Thermodynamic arguments also support the possibility for PT in the reactions of ${ }^{\mathrm{X}} \mathrm{ArOH}\left(\mathrm{X}=\mathrm{NO}_{2}\right.$ and $\left.\mathrm{CF}_{3}\right)$, comparing the free energies for PT and CPET as a function of the $\mathrm{X}$ substituent in ${ }^{\mathrm{x}} \mathrm{ArOH}$ (Fig. 5). $\Delta G_{\mathrm{CPET}}$ is estimated as the difference of the phenol BDFE and the BDE of the copper(II)-aqua complex, 3a. $\Delta G_{\mathrm{PT}}$ is roughly approximated as the difference of the phenol $\mathrm{p} K_{\mathrm{a}}$ in DMSO and the $\mathrm{p} K_{\mathrm{a}}$ of the copper(III)-aqua complex $3 \mathrm{a}$ in THF, which should capture the trend (the various phenol $\mathrm{p} K_{\mathrm{a}} \mathrm{s}$ likely being shifted by a constant amount between DMSO and THF) and should be more negative than the true value in THF (the less polar solvent disfavoring the formation of charged species in the equilibrium $\mathrm{ArOH}+\mathrm{LCuOH} \leftrightharpoons \mathrm{ArO}^{-}+\mathrm{LCuOH}_{2}^{+}$). Fig. 5 shows that $\Delta G_{\mathrm{PT}}$ is greater than $\Delta G_{\mathrm{CPET}}$ by a significant amount for most of the phenols, consistent with CPET being more favorable than the corresponding PT/ET process. However, for $\mathrm{X}=\mathrm{NO}_{2}$ and $\mathrm{CF}_{3}, \Delta G_{\mathrm{PT}}$ comes much closer and is

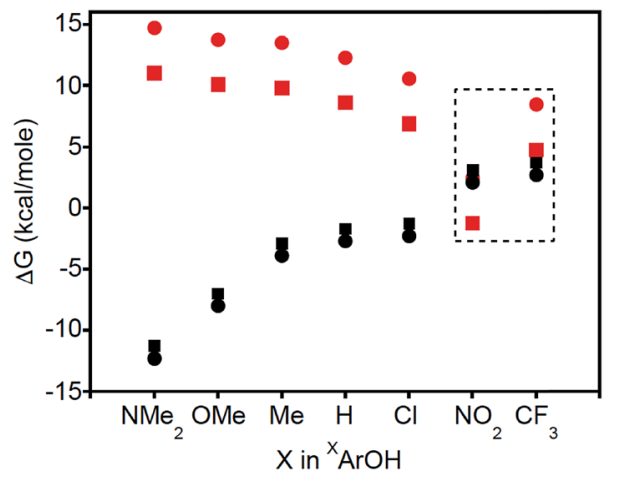

Fig. 5 Plot of $\Delta G$ for corresponding PT (red) or CPET (black) reactions with $2 \mathrm{a}$ (squares) and $\mathbf{2 b}$ (circles). The dashed region represents where there is potential for thermodynamic overlap (i.e., both PT and CPET are feasible). Estimated errors in $\Delta G$ are $\pm 3 \mathrm{kcal} \mathrm{mol}^{-1}$ (error bars not shown for clarity).

likely comparable to $\Delta G_{\mathrm{CPET}}$, so PT may be thermodynamically competitive with CPET in these cases. ${ }^{30}$ It has been suggested that under such circumstances, there can be a change in the nature of the transition state; "valence bond mixing creates a concerted reaction with PT character, followed by ET" ${ }^{6 \boldsymbol{b}}$ In this case, however, competitive pathways are indicated by the appearance of phenoxide and aquo complexes as intermediates, rather than the evolution of a single transition state. Additionally, we note that there is a conspicuous discontinuity in the Hammett plots $\left(\log k_{\mathrm{X}} / k_{\mathrm{H}}\right.$ is plotted $v s$. the $\sigma_{\mathrm{p}}$ for the respective para-substituents in ${ }^{\mathrm{X}} \mathrm{ArOH}$ ), particularly for $\mathrm{X}=\mathrm{NO}_{2}$ and $\mathrm{CF}_{3}$ (Fig. S32†).

In general, metal-mediated PCET reactions involving initial PT from single donor site to single acceptor site are rare. In one case, manganese(III)- and iron(III)-oxo complexes featuring extremely basic oxo ligands were shown to change mechanism from CPET to PT in their reactions with phenols. ${ }^{31}$ Notably, however, product analysis showed that the subsequent electron transfer after PT did not occur, even with fairly reducing phenolic substrates. Other studies report initial proton transfer occurring in aqueous PCET reactions of substituted phenols at higher $\mathrm{pH}$, but these reactions are often reminiscent of sequential-proton-loss-electron-transfer (SPLET) in which hydroxide (or buffer) serves to deprotonate the phenol prior to one electron oxidation of the phenoxide. ${ }^{32}$ Still other reports of PT-initiated PCET reactions involving ruthenium(Iv)-oxo or osmium(III)-amino complexes have also been shown to involve exogenous hydroxide as a proton acceptor. ${ }^{33}$ In such systems it is generally difficult to distinguish between a concerted and sequential process. Most common are examples in which metalmediated phenol-based oxidations have been shown to proceed via concerted processes. These include reactions mediated by metal-superoxo, ${ }^{34}$-oxo, ${ }^{29 b, 35}$ and -hydroxo/alkoxo species, ${ }^{23 b, 36}$ as well as metal based oxidants featuring pendant basic functionalities, which are often an amine or carboxylate group. ${ }^{23 c, 37}$ In some cases an "ET-first" type mechanism has been proposed, as in the case of two $\mu$-peroxo/ $\mu$-oxo-dicopper species. ${ }^{13}$ There are also a number of studies which report a change in mechanism from a concerted process to a sequential ET/PT process, 
induced by increasing the overall driving force for electrontransfer either by increasing the reduction potential of the $\mathrm{H}$-atom abstractor or by decreasing the oxidation potential of the phenolic substrate. ${ }^{27 b, 33}$ In one instance mechanistic changeover has even been induced by simply changing the temperature. $^{38} \mathrm{~A}$ unifying theme amongst all of the above examples is that the transition metal based oxidants are supported by neutral/monoanionic ligand frameworks and possess an overall cationic charge. Consequently, the reactive species most commonly behave as electrophiles in these studies, thus precluding pathways involving an initial PT step.

These characteristics contrast with those of $\mathbf{2 a}$, which is a reasonably strong base (estimated $\mathrm{p} K_{\mathrm{a}} \sim 11.7$ for $4 \mathrm{a}$ in THF). By analogy to the above cases in which an "ET-first" mechanism was induced by decreasing the oxidation potential of the phenolic substrate (i.e. making the substrate more electronrich), we propose that decreasing the $\mathrm{p} K_{\mathrm{a}}$ of the phenolic substrate (making it more electron-poor) induces a "PT-first" mechanism in the reaction between $2 \mathrm{a}$ and ${ }^{\mathrm{NO}_{2}} \mathrm{ArOH}$. As an illustration of this point, it is instructive to compare this reaction with that between a ruthenium(III)-pterin complex and ${ }^{\mathrm{NO}_{2}} \mathrm{ArOH}$, which is proposed to proceed via a CPET pathway. ${ }^{23 c}$ The thermodynamic driving force for a CPET reaction in both these cases is very similar (BDE of 3a is $90 \mathrm{kcal} \mathrm{mol}^{-1}$ while that for the $\mathrm{N}-\mathrm{H}$ bond formed in the ruthenium-pterin complex is $\sim 89 \mathrm{kcal} \mathrm{mol}^{-1}$ ). However, the ruthenium(III)-pterin is significantly less basic $\left(\mathrm{p} K_{\mathrm{a}} \sim 12\right.$ in MeCN) than ${ }^{\mathrm{NO}_{2}} \mathrm{ArOH}\left(\mathrm{p} K_{\mathrm{a}} \sim 20.7\right.$ in $\mathrm{MeCN}$ ), ${ }^{23 c}$ which results in an unfavorable thermodynamic driving force for a proton transfer from ${ }^{\mathrm{NO}_{2}} \mathrm{ArOH}$ in that solvent $\left(\sim 9 \mathrm{p} K_{\mathrm{a}}\right.$ units, $\left.\sim 12 \mathrm{kcal} \mathrm{mol}{ }^{-1}\right)$. Consequently, the reaction proceeds through the more feasible CPET mechanism. In contrast, the copper(III)-aqua complex (4a) has a p $K_{\mathrm{a}} \sim 11.7$ (in THF) so proton transfer to ${ }^{{ }^{\mathrm{NO}}}{ }^{2} \mathrm{ArOH}\left(\mathrm{p} K_{\mathrm{a}} \sim 13.1\right.$ in THF) ${ }^{29}$ is clearly much more energetically favorable, indicating the feasibility of contribution from a PT/ET pathway.

The above argument raises an important question: if the thermodynamic driving force of the CPET pathway is comparable to that for the corresponding PT pathway, what factors determine the contribution from each pathway in the overall mechanism? Computational studies aimed at addressing such a dichotomy between concerted and sequential PT/ET pathways suggest that factors such as intrinsic proton transfer barrier and nature of coupling between the proton and electron are often key determinants under such circumstances. ${ }^{39}$ While in many cases the CPET pathway is strongly favored, such a mechanistic cross-over seems plausible, particularly in cases where the free energies are competitive and where the proton transfer occurs between electronegative $\mathrm{O}$ or $\mathrm{N}$ atoms so that the intrinsic barrier is small. For instance, a gas phase study focused on understanding such competition between PT versus HAT in reactions of enol radical cations and aldehydes concluded that when the enthalpies of the PT and HAT $\left(\Delta H_{\mathrm{PT}}\right.$ and $\Delta H_{\mathrm{HAT}}$, respectively) were similar, the PT pathway dominated. The authors attribute this to a much more stable transition state involving H-bonding in the case of PT and a non-negligible intrinsic barrier in the case of the HAT pathway. ${ }^{40}$ While this system is significantly different than the solution phase studies discussed above, it serves to highlight the importance of such factors as the nature of the transition state and intrinsic barriers in the phenol reactions of 2a, and in these types of PCET reactions in general.

\section{Summary and conclusions}

The reactivity of the copper(III)-hydroxide complexes $\mathbf{2 a}$ and $\mathbf{2 b}$ in THF with a series of phenols ${ }^{\mathrm{x}} \mathrm{ArOH}$ with para substituents $\mathrm{X}$ having a range of electron donor capabilities was probed using low temperature stopped-flow methods. Second-order rate constants for the reactions were measured and found to vary over a wide range $\left(\sim 10^{5} \mathrm{M}^{-1} \mathrm{~s}^{-1}\right)$. For $\mathrm{X}=\mathrm{NMe}_{2}, \mathrm{OMe}, \mathrm{Me}, \mathrm{H}$, and $\mathrm{Cl}$, direct formation of phenoxyl radical species is implicated, whereas for $\mathrm{X}=\mathrm{NO}_{2}$ (and likely for $\mathrm{CF}_{3}$ as well), the phenolate ${ }^{\mathrm{x}} \mathrm{ArO}^{-}$formed and the kinetics for decay of $\mathbf{2 a}$ and $\mathbf{2 b}$ were best fit to a model involving the formation of an intermediate identified tentatively on the basis of independent experiments as the copper(III)-aqua complex 4 a. These results, in conjunction with evaluation of the trends in $\log k$ as a function of the phenol thermodynamic parameters $\log K, E_{1 / 2}$, and $\mathrm{p} K_{\mathrm{a}}$ are consistent with a CPET mechanism for the series $\mathrm{X}=$ $\mathrm{NMe}_{2}, \mathrm{OMe}, \mathrm{Me}, \mathrm{H}$, and $\mathrm{Cl}$, but with an additional contribution from sequential PT/ET for the most acidic phenols with $\mathrm{X}=\mathrm{NO}_{2}$ and $\mathrm{CF}_{3}$. These results serve to elucidate the finer nuances of the hydrogen atom abstraction ability of the reactive copper(III) hydroxide species, particularly highlighting the important role of its basicity in such reactions. More generally, these findings provide significant insights into fundamental aspects of the reactivity of the $[\mathrm{CuOH}]^{2+}$ core, which may play a key role in oxidations promoted by enzymes and other catalysts.

\section{Acknowledgements}

We thank the NIH (grant R37GM47365 to W. B. T. and grant 5R01GM050422 to J. M. M.) for financial support. We acknowledge Dr Bradley McKeown for his help with the stopped-flow measurements. X-ray diffraction experiments were performed using a crystal diffractometer acquired through NSFMRI Award CHE-1229400.

\section{Notes and references}

1 (a) L. M. Mirica, X. Ottenwaelder and T. D. P. Stack, Chem. Rev., 2004, 104, 1013-1045; (b) E. Lewis and W. B. Tolman, Chem. Rev., 2004, 104, 1047-1076; (c) J. Y. Lee and K. D. Karlin, Curr. Opin. Chem. Biol., 2015, 25, 184-193; (d) R. A. Himes and K. D. Karlin, Curr. Opin. Chem. Biol., 2009, 13, 119-131; (e) S. Itoh, Acc. Chem. Res., 2015, 48, 20662074; $(f)$ N. Gagnon and W. B. Tolman, Acc. Chem. Res., 2015, 48, 2126-2131.

2 (a) P. J. Donoghue, J. Tehranchi, C. J. Cramer, R. Sarangi, E. I. Solomon and W. B. Tolman, J. Am. Chem. Soc., 2011, 133, 17602-17605; (b) D. Dhar and W. B. Tolman, J. Am. Chem. Soc., 2015, 137, 1322-1329; (c) D. Dhar, G. M. Yee, A. D. Spaeth, D. W. Boyce, H. Zhang, B. Dereli, 
C. J. Cramer and W. B. Tolman, J. Am. Chem. Soc., 2016, 138, 356-368.

3 (a) N. J. Rijs, T. Weiske, M. Schlangen and H. Schwarz, Chem. Phys. Lett., 2014, 608, 408-424; (b) N. Dietl, M. Schlangen and H. Schwarz, Angew. Chem., Int. Ed., 2012, 51, 5544-5555; (c) N. Dietl, C. van der Linde, M. Schlangen, M. K. Beyer and H. Schwarz, Angew. Chem., Int. Ed., 2011, 50, 4966-4969; (d) D. Schröder, M. C. Holthausen and H. Schwarz, J. Phys. Chem. B, 2004, 108, 14407-14416.

4 (a) A. Decker and E. I. Solomon, Curr. Opin. Chem. Biol., 2005, 9, 152-163; (b) T. Kamachi, N. Kihara, Y. Shiota and K. Yoshizawa, Inorg. Chem., 2005, 44, 4226-4236; (c) K. Yoshizawa, N. Kihara, T. Kamachi and Y. Shiota, Inorg. Chem., 2006, 45, 3034-3041; (d) P. Comba, S. Knoppe, B. Martin, G. Rajaraman, C. Rolli, B. Shapiro and T. Stork, Chem.-Eur. J., 2008, 14, 344-357; (e) S. Kim, J. Ståhlberg and M. Sandgren, Proc. Natl. Acad. Sci. U. S. A., 2014, 111, 149-154.

5 (a) J. J. Warren and J. M. Mayer, Biochemistry, 2015, 54, 18631878; (b) C. Costentin, M. Robert, J.-M. Savéant and C. Tard, Acc. Chem. Res., 2014, 47, 271-280; (c) D. R. Weinberg, C. J. Gagliardi, J. F. Hull, C. F. Murphy, C. A. Kent, B. C. Westlake, A. Paul, D. H. Ess, D. G. McCafferty and T. J. Meyer, Chem. Rev., 2012, 112, 4016-4093; (d) C. Costentin, M. Robert and J.-M. Savéant, Acc. Chem. Res., 2010, 43, 1019-1029; (e) S. Hammes-Schiffer, Acc. Chem. Res., 2009, 42, 1881-1889; (f) J. M. Mayer, Annu. Rev. Phys. Chem., 2004, 55, 363-390.

6 (a) A. S. Borovik, Chem. Soc. Rev., 2011, 40, 1870-1874; (b) D. Usharani, D. C. Lacy, A. S. Borovik and S. Shaik, J. Am. Chem. Soc., 2013, 135, 17090-17104; (c) Y. Morimoto, J. Park, T. Suenobu, Y.-M. Lee, W. Nam and S. Fukuzumi, Inorg. Chem., 2012, 51, 10025-10036.

7 For example, see: (a) E. C. Minnihan, D. G. Nocera and J. Stubbe, Acc. Chem. Res., 2013, 46, 2524-2535; (b) J. P. McEvoy and G. W. Brudvig, Chem. Rev., 2006, 106, 4455-4483; (c) V. R. I. Kaila, M. I. Verkhovsky and M. Wikström, Chem. Rev., 2010, 110, 7062-7081; (d) S. Yoshikawa and A. Shimada, Chem. Rev., 2015, 115, 19361989.

8 J. J. Warren, T. A. Tronic and J. M. Mayer, Chem. Rev., 2010, 110, 6961-7001.

9 F. G. Bordwell and J. Cheng, J. Am. Chem. Soc., 1991, 113, 1736-1743.

10 Olis GlobalWorks 3D Analysis Software. For illustrative references see (a) Z. Ma, H. R. Williamson and V. L. Davidson, Proc. Natl. Acad. Sci. U. S. A., 2015, 112, 10896-10901; (b) R. J. DeSa and I. B. C. Matheson, Methods Enzymol., 2004, 384, 1-8; (c) E. R. Henry and J. Hofrichter, Methods Enzymol., 1992, 210, 129-192; (d) N. Sreerama, S. Y. Venyaminov and R. W. Woody, Anal. Biochem., 2001, 299, 271-274.

11 In all cases we assume that the rates measured correspond to the rate of the HAT/CPET reaction between $\mathbf{2 a / b}$ and $\mathrm{ArOH}$. It is also possible that the organic product of this reaction could further react with additional equivalents of $2 \mathbf{a} / \mathbf{b}$, but we assume here that such secondary reactions are negligible. This possibility is currently under further investigation.

12 L. L. Miller and R. F. Stewart, J. Org. Chem., 1978, 43, 15801586.

13 T. Osako, K. Ohkubo, M. Taki, Y. Tachi, S. Fukuzumi and S. Itoh, J. Am. Chem. Soc., 2003, 125, 11027-11033.

14 V. W. Manner, T. F. Markle, J. H. Feudenthal, J. P. Roth and J. M. Mayer, Chem. Commun., 2008, 256-258.

15 (a) P. Verma, R. S. Pratt, T. Storr, E. C. Wasinger and T. D. P. Stack, Proc. Natl. Acad. Sci. U. S. A., 2011, 108, 18600-18605; (b) B. A. Jazdzewski, P. L. Holland, M. Pink, V. G. Young, D. J. E. Spencer and W. B. Tolman, Inorg. Chem., 2001, 40, 6097-6107; (c) B. A. Jazdzewski and W. B. Tolman, Coord. Chem. Rev., 2000, 200-202, 633-685.

16 P. Eyer and E. Lengfelder, Biochem. Pharmacol., 1984, 33, 1005-1013.

17 We note that there is a possibility that the formed nitrophenolate anion might not be present as free phenolate in the reaction mixture and could potentially interact with the copper(II)-solvato adduct formed in situ to yield a copper(II)-phenolate complex.

18 For reactions of $\mathbf{2 b}$ with ${ }^{\mathrm{NO}_{2}} \mathrm{ArOH}$ it is expected that the CT feature corresponding to the ${ }^{\mathrm{NO}_{2}} \mathrm{ArO}^{-}$at $400 \mathrm{~nm}$, if present, would be significantly less intense than for reactions of $2 \mathrm{a}$ with ${ }^{\mathrm{NO}_{2}} \mathrm{ArOH}$, due to (1) the significant contribution from self-decay in THF and (2) the much less favorable thermodynamics for proton transfer.

19 We hypothesize that this also occurs in the pseudo-first order runs, but is accounted for in the self-decay component of the reaction observed as a non-zero $y$-intercept in the second order $k$ vs. $\left[{ }^{\mathrm{x}} \mathrm{ArOH}\right]_{0}$ plots, which also agree with the previously measured self-decay rates.

20 For a representative EPR spectrum of $\mathrm{FcBF}_{4}$ see S. P. Bew, M. R. Cheesman and S. V. Sharma, Chem. Commun., 2008, 5731-5733.

21 P. Neta and J. Grodlowski, J. Phys. Chem. Ref. Data, 2005, 34, 109-199.

22 We note however that there are subtle differences in these independent spectra for $\mathbf{4 a}$ and that of the intermediate; particularly in some cases the independent spectra for $\mathbf{4 a}$ depict slightly more pronounced shoulder absorption features at $\sim 830 \mathrm{~nm}$. We attribute these differences to the likely presence of ${ }^{\mathrm{NO}_{2}} \mathrm{ArO}^{-} / \mathrm{NO}_{2} \mathrm{ArOH}$ in the latter reaction mixtures.

23 (a) E. A. Mader and J. M. Mayer, Inorg. Chem., 2010, 49, 36853687; (b) G. B. Wijeratne, B. Corzine, V. W. Day and T. A. Jackson, Inorg. Chem., 2014, 53, 7622-7634; (c) S. Miyazaki, T. Kojima, J. M. Mayer and S. Fukuzumi, J. Am. Chem. Soc., 2009, 131, 11615-11624.

24 (a) D. W. Snelgrove, J. Lusztyk, J. T. Banks, P. Mulder and K. U. Ingold, J. Am. Chem. Soc., 2001, 123, 469-477; (b) M. F. Nielsen and K. U. Ingold, J. Am. Chem. Soc., 2006, 128, 1172-1182; (c) G. Litwinienko and K. U. Ingold, Acc. Chem. Res., 2007, 40, 222-230; (d) J. J. Warren and J. M. Mayer, Proc. Natl. Acad. Sci. U. S. A., 2010, 107, 52825287; (e) R. Amorati and L. Valgimigli, Org. Biomol. Chem., 2012, 10, 4147-4158; (f) M. Jha and D. A. Pratt, Chem. 
Commun., 2008, 1252-1254; (g) L. Valgimigli, J. T. Banks, K. U. Ingold and J. Lusztyk, J. Am. Chem. Soc., 1995, 117, 9966-9971.

25 M. H. Abraham, P. L. Grellier, D. B. Prior, P. P. Duce, J. J. Morris and P. J. Taylor, J. Chem. Soc., Perkin Trans. 2, 1989, 699-711.

26 An implicit assumption made in using these conversions is that the abstractor behaves identically in the two solvents. While Ingold and co-workers have previously demonstrated that such kinetic solvent effects are independent of the nature of the abstractor (ref. 24g), we acknowledge that this might not be completely true for $\mathbf{2 a} / \mathbf{b}$, as they could act as potential hydrogen bond donors and behave differently in THF and DMSO. However, this is expected to be a systematic trend for a given abstractor and hence these conversions are useful in predicting trends across their reactions with a series of phenols.

27 (a) J. M. Mayer, Acc. Chem. Res., 2010, 44, 36-46; (b) J. M. Mayer, J. Phys. Chem. Lett., 2011, 2, 1481-1489.

28 (a) J. Nomrowski and O. Wenger, Inorg. Chem., 2015, 54, 3680-3687; (b) S. Kundu, E. Micelli, E. R. Farquhar and K. Ray, Dalton Trans., 2014, 43, 4264-4267.

29 (a) M. Sjödin, S. Styring, J. Wolpher, Y. Xu, L. Sun and L. Hammarström, J. Am. Chem. Soc., 2005, 127, 3855-3863; (b) S. Ohzu, T. Ishizuka, H. Kotani and T. Kojima, Chem. Commun., 2014, 50, 15018-15021.

30 Consistent with this conclusion, we found the $\mathrm{p} K_{\mathrm{a}}$ of ${ }^{\mathrm{NO}_{2}} \mathrm{ArOH}$ in THF to be 13.1 (see Fig. S33 and Table S5 $\dagger$ ), close to the value reported in DMSO (Table 1).
31 R. Gupta and A. S. Borovik, J. Am. Chem. Soc., 2003, 125, 13234-13242.

32 C. Costentin, C. Louault, M. Robert and J.-M. Savéant, Proc. Natl. Acad. Sci. U. S. A., 2009, 106, 18143-18148.

33 (a) E.-S. El-Samanody, K. D. Demadis, T. J. Meyer and P. S. White, Inorg. Chem., 2001, 40, 3677-3686; (b) E. L. Lebeau, R. A. Binstead and T. J. Meyer, J. Am. Chem. Soc., 2001, 123, 10535-10544.

34 Y. J. Lee, R. L. Peterson, K. Ohkubo, I. Garcia-Bosch, R. A. Himes, J. Woertink, C. D. Moore, E. I. Solomon, S. Fukuzumi and K. D. Karlin, J. Am. Chem. Soc., 2014, 136, 9925-9937.

35 H. Kotani, S. Kaida, T. Ishizuka, M. Sakaguchi, T. Ogura, Y. Shiota, K. Yoshizawa and T. Kojima, Chem. Sci., 2015, 6, 945-955.

36 G. B. Wijeratne, V. W. Day and T. A. Jackson, Dalton Trans., 2015, 44, 3295-3306.

37 J. J. Warren and J. M. Mayer, J. Am. Chem. Soc., 2011, 133, 8544-8551.

38 J. Jung, S. Kim, Y.-M. Lee, W. Nam and S. Fukuzumi, Angew. Chem., Int. Ed., 2016, 55, 7450-7454.

39 (a) S. Hammes-Schiffer and A. A. Stuchebrukhov, Chem. Rev., 2010, 110, 6939-6960; (b) J. S. Kretchmer and T. F. Miller, Inorg. Chem., 2016, 55, 1022-1031.

40 H.-E. Audier, G. Bouchoux, P. Mourgues and F. PenaoudBerruyer, Org. Mass Spectrom., 1992, 27, 439-442. 